Check for updates

Cite this: RSC Adv., 2019, 9, 2572

\title{
Effect of resveratrol on drug resistance in colon cancer chemotherapy
}

\begin{abstract}
Lu Huang, (DD ${ }^{a}$ Sheng Zhang, ${ }^{a}$ Jun Zhou ${ }^{a}$ and Xiangzhou Li ${ }^{\star a b}$
To investigate the effects of resveratrol on the drug resistance of 5-FU in the colon cancer chemotherapy, an MTT assay was used to detect the effects of 5-FU and resveratrol combined with 5-FU on the proliferation of the LoVo and SW480 cell lines. Flow cytometry was used to detect the effect of 5-FU combined with resveratrol on the survival rate of the LoVo and SW480 cells. A western blot was used to detect the expression levels of the proteins associated with colon cancer. After flow sorting, the percentage of the SW480 and the LoVo cell line CD133 ${ }^{+}$was $97.5 \%$ and $95.8 \%$, respectively. The cells cultured in vitro showed more rapid cell proliferation and differentiation. The MTT assay showed that as compared with the survival rate of the blank group LoVo and CD133 ${ }^{+}$LoVo cells, the survival rate of the cells containing the 5FU group was lower $(P<0.05)$. When 5 -FU was used in combination with different concentrations of resveratrol, the abovementioned phenomenon was more prominent. The sorted colon cancer cells have dry stem cells, and the sorted $\mathrm{CD}_{133^{+}}$cells are more resistant to drugs; the combination of resveratrol and 5-FU has the best effect on the colon cancer cells. Preliminary studies on the mechanism of action of the drug show that a combination of 5-FU and resveratrol regulates apoptosis in $\mathrm{CD}_{133^{+}}$colon cancer stem cells by regulating the $B A X$ gene; however, more complex mechanisms may also be involved.
\end{abstract}

Received 9th October 2018

Accepted 2nd January 2019

DOI: $10.1039 / \mathrm{c} 8 \mathrm{ra0} 0364 a$

rsc.li/rsc-advances the positive role of stem cell symmetry and asymmetric divisions in the development of cancer resistance.

Resveratrol (RES) is a natural active compound ${ }^{13}$ mainly extracted from peanuts, grapes, Polygonum cuspidatum, and other plants. ${ }^{14}$ It is a non-flavonoid polyphenol, insoluble in water, but soluble in organic solvents such as ethanol and acetone. It exists in the free state and forms glycosides under natural conditions. 5-FU is a commonly used chemotherapy drug for colorectal cancer treatment. As its dose increases, the side effects of the drug also increase and resistance to the drug develops frequently. Therefore, its clinical application is limited. ${ }^{15}$ Some studies have shown that a combination of chemotherapeutic drugs and traditional Chinese medicine not only can reduce adverse drug reactions but can also produce synergies between drugs and promote better efficacy. ${ }^{\mathbf{1 6}}$ Resveratrol has been reported to exhibit cellular anticancer activity in breast cancer, ${ }^{17}$ skin cancer, ${ }^{18}$ and liver cancer. ${ }^{19}$ More importantly, it has been found that resveratrol can be combined with chemotherapeutics to reduce drug resistance during some cancer treatments. Laura H. Engelke ${ }^{20}$ reported the effects of ellagic acid and resveratrol on the epithelial ovarian cancer cell line A2780. Sin Ho Kweon ${ }^{21}$ reported that resveratrol-mediated downregulation of MRP1 was associated with the reversal of resistance to doxorubicin in acute leukemia cells. $\mathrm{Xu}^{22}$ reported that resveratrol inhibited the epithelial-mesenchymal transitions by regulating the PTEN-Akt signaling pathway in gastric cancer. Jie Meng $^{23}$ reported the use of liposome-encapsulated resveratrol and paclitaxel in the treatment of breast cancer cell resistance reversal.
${ }^{a}$ School of Materials Science and Engineering, Central South University of
Technology, 498 South Shaoshan Ave, Changsha 410004, Hunan, China

${ }^{b}$ National Engineering Laboratory of Southern Forestry Ecological Application Technology, Changsha 410004, China 


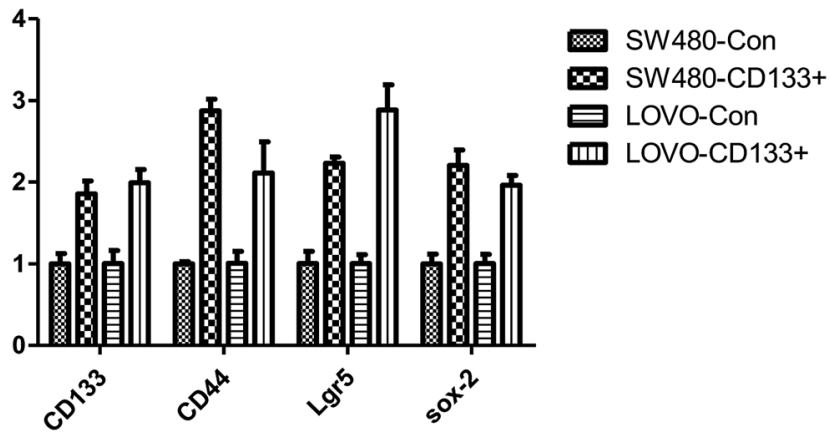

Fig. 1 Expression data of $\mathrm{CD}_{133^{+}}$and other stem cell markers in colon cancer cell.
In summary, resveratrol demonstrates good resistance to drugs in the treatment of multiple cancers with chemotherapeutic agents. However, its effects have not been reported in colon cancer cells. In this study, the effect of resveratrol combined with 5-FU has been investigated on colon cancer cells and stem cells. We have confirmed the effect of resveratrol on drug resistance in colon cancer cells and determined its mechanism of action at the gene level.

\section{Results and discussion}

\section{Cancer stem cell selection and separation}

CD133, CD44, Lgr5, and Sox-2 are tumor marker genes. ${ }^{24}$ The results of the cancer stem cell sorting (Fig. 1) show that the expression levels of these four tumor markers are significantly

\section{LOVO}

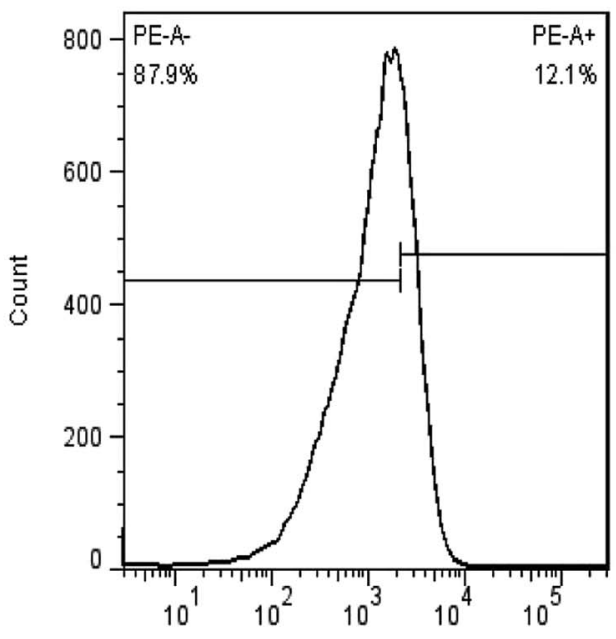

PE-A

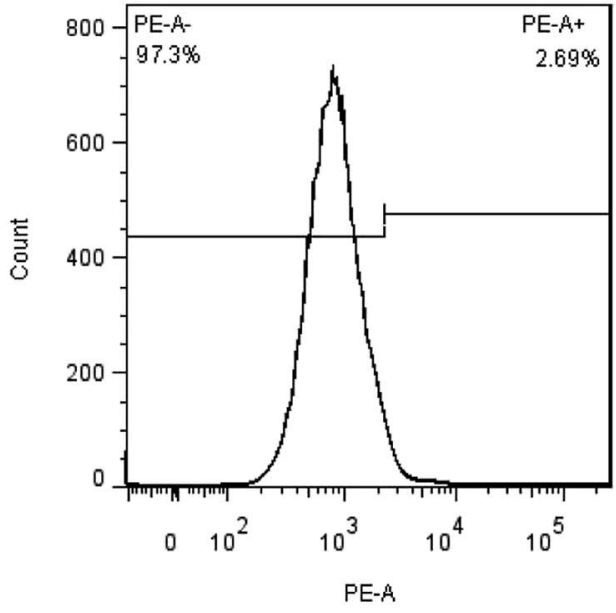

LOVO CD133+

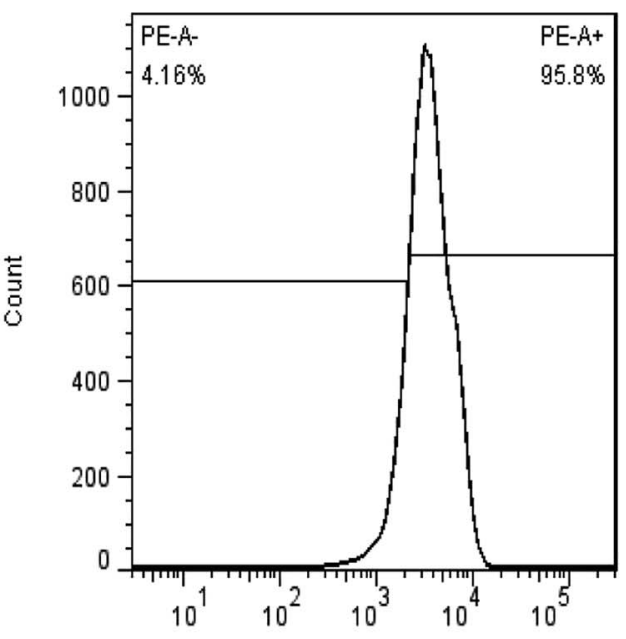

PE-A
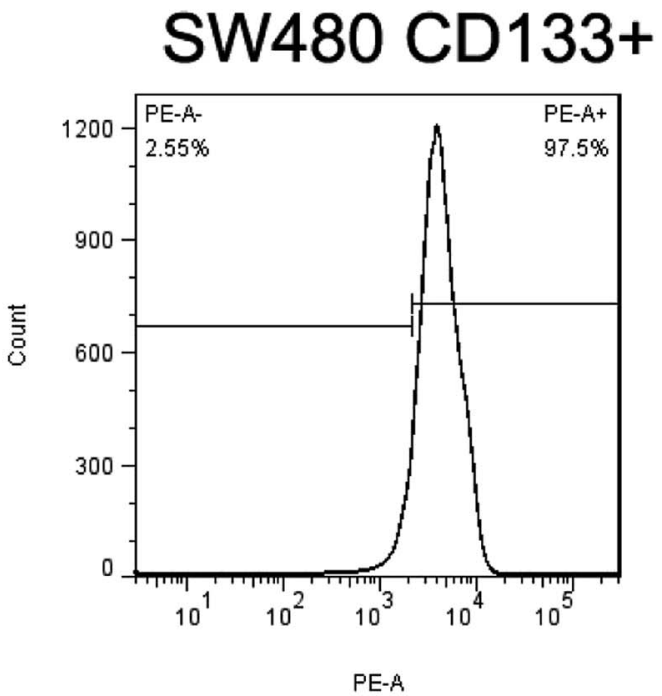

Fig. 2 Flow detection of the results of cell separation. 
higher in cancer stem cells $(P<0.01)$ than those in the normal cells. The isolated stem cells were confirmed to be exact.

\section{Flow cytometry verification}

Flow cytometry results (Fig. 2) showed that the $\mathrm{CD} 133^{+}$cells reached $95.8 \%$ and $97.5 \%$ in colorectal cancer LoVo and SW480 cells after tumor cell sorting, respectively. Experimental results also confirmed that the isolated stem cells were exact.

\section{In vitro ball validation results}

As shown in Fig. 3 and 4, the LoVo and SW480 cells are more capable of reproduction after sorting and have more ability to differentiate than the unsorted stem cells.
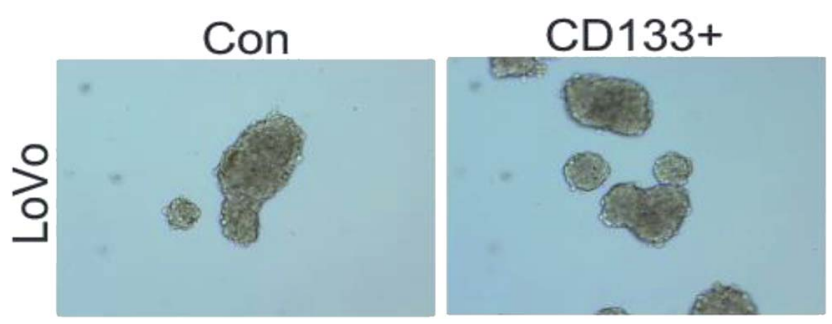

Fig. 3 LoVo balling in vitro before and after separation.

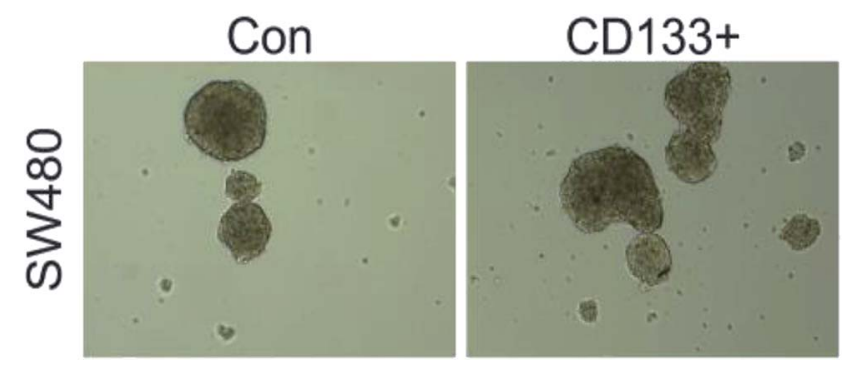

Fig. 4 SW480 balling in vitro before and after separation.

\section{MTT assay validates the effect of resveratrol on the drug} resistance of $\mathbf{S W 4 8 0}$ stem cells

The experimental results obtained via the MTT assays when 5FU at different concentrations was reacted with resveratrol are shown in Table 1. The experimental results obtained when the same concentration of 5-FU was combined with different concentrations of resveratrol according to the previous method are shown in Table 2.

Fig. 5 shows that the $\mathrm{CD} 133^{+}$SW480 cells were added to 5 -FU after being compared with the parental cells. The cell survival

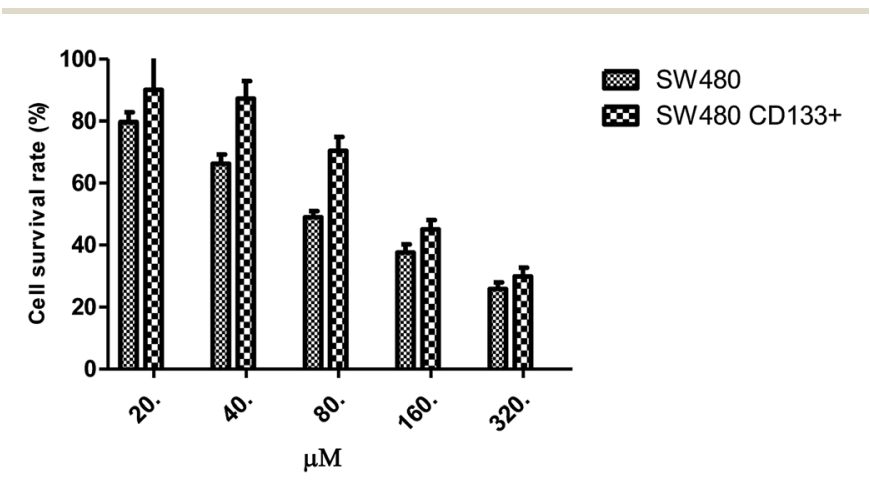

Fig. 5 Effect of FU on the survival rate of SW480 cells and SW480 tumorigenic stem cells.

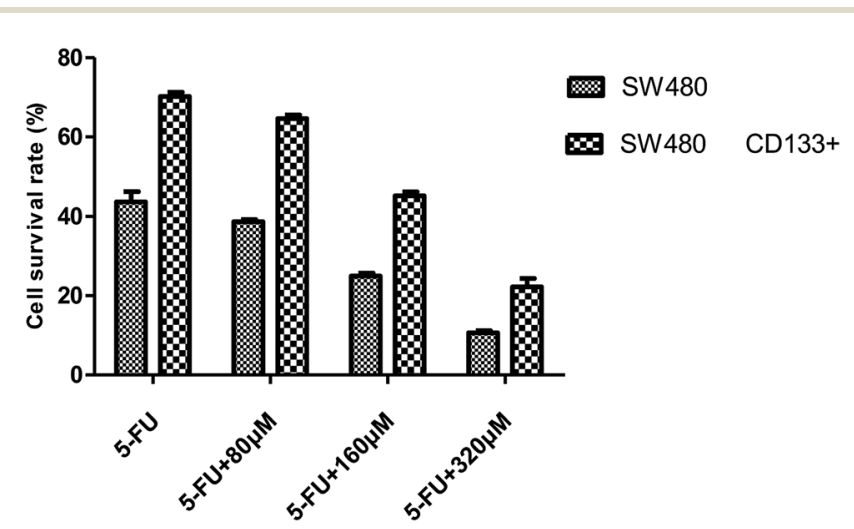

Fig. 6 Bar graph of survival rate of SW480 cells and SW480 CD133 cells.

Table 1 Effects of 5-FU at different concentrations on the survival rate of SW480 cells and SW480 tumorigenic stem cells

\begin{tabular}{|c|c|c|c|c|c|c|}
\hline & $0 \mu \mathrm{M}$ & $20 \mu \mathrm{M}$ & $40 \mu \mathrm{M}$ & $80 \mu \mathrm{M}$ & $160 \mu \mathrm{M}$ & $320 \mu \mathrm{M}$ \\
\hline SW480 & $1.210 \pm 0.082$ & $0.964 \pm 0.038$ & $0.802 \pm 0.037$ & $0.592 \pm 0.024$ & $0.454 \pm 0.032$ & $0.313 \pm 0.026$ \\
\hline SW480 CD133 ${ }^{+}$ & $1.318 \pm 0.092$ & $1.187 \pm 0.136$ & $1.149 \pm 0.075$ & $0.929 \pm 0.059$ & $0.594 \pm 0.040$ & $0.395 \pm 0.037$ \\
\hline
\end{tabular}

Table 2 Effects of 5-Fu at the same concentration and resveratrol at different concentrations on the survival rate of SW480 cells and SW480 tumorigenic stem cells

\begin{tabular}{llllrr}
\hline & $0 \mu \mathrm{M}$ & $5-\mathrm{FU}$ & $5-\mathrm{FU}+80 \mu \mathrm{M}$ & $5-\mathrm{FU}+160 \mu \mathrm{M}$ & $5 \mathrm{FU}+320 \mu \mathrm{M}$ \\
\hline SW480 & $1.324 \pm 0.023$ & $0.723 \pm 0.021$ & $0.683 \pm 0.020$ & $0.441 \pm 0.028$ \\
SW480 CD133 & $1.495 \pm 0.014$ & $1.050 \pm 0.036$ & $0.966 \pm 0.030$ & $0.676 \pm 0.035$
\end{tabular}


Table 3 Effects of 5-FU at different concentrations on the survival rate of LoVo cells and LoVo CD133 ${ }^{+}$tumorigenic stem cells

\begin{tabular}{|c|c|c|c|c|c|c|}
\hline & $0 \mu \mathrm{M}$ & $10 \mu \mathrm{M}$ & $20 \mu \mathrm{M}$ & $40 \mu \mathrm{M}$ & $80 \mu \mathrm{M}$ & $160 \mu \mathrm{M}$ \\
\hline LoVo & $0.476 \pm 0.040$ & $0.254 \pm 0.016$ & $0.203 \pm 0.014$ & $0.199 \pm 0.015$ & $0.173 \pm 0.012$ & $0.121 \pm 0.007$ \\
\hline LoVo CD $133^{+}$ & $1.129 \pm 0.323$ & $1.041 \pm 0.009$ & $0.870 \pm 0.067$ & $0.692 \pm 0.026$ & $0.421 \pm 0.061$ & $0.250 \pm 0.035$ \\
\hline
\end{tabular}

Table 4 Effects of 5-Fu at the same concentration and resveratrol at different concentrations on the survival rate of LoVo cells and LoVo CD133 ${ }^{+}$ tumorigenic stem cells

\begin{tabular}{|c|c|c|c|c|c|c|}
\hline & $0 \mu \mathrm{M}$ & $10 \mu \mathrm{M}$ & $20 \mu \mathrm{M}$ & $40 \mu \mathrm{M}$ & $80 \mu \mathrm{M}$ & $160 \mu \mathrm{M}$ \\
\hline LoVo & $0.476 \pm 0.040$ & $0.254 \pm 0.016$ & $0.203 \pm 0.014$ & $0.199 \pm 0.015$ & $0.173 \pm 0.012$ & $0.121 \pm 0.007$ \\
\hline LoVo CD133 ${ }^{+}$ & $1.129 \pm 0.323$ & $1.041 \pm 0.009$ & $0.870 \pm 0.067$ & $0.692 \pm 0.026$ & $0.421 \pm 0.061$ & $0.250 \pm 0.035$ \\
\hline
\end{tabular}

rate of $\mathrm{CD} 133^{+}$SW480 cells decreased by $25.852 \%$ from $79.656 \%$, and that of the parental cells decreased by $29.94 \%$ from $90.076 \%$. The $\mathrm{CD}_{133^{+}}$SW480 cells were therefore less sensitive to 5-FU as compared to the parental cells. 5-FU combined with resveratrol acted on the colon cancer cell line SW480 and on the sorted CD133 ${ }^{+}$SW480 stem cells (Fig. 6). Preliminary results showed that with an increase in the resveratrol concentration, the survival rate of the SW480 cells decreased from $43.68 \%$ to $10.634 \%$ and the survival rate of the $\mathrm{CD}_{133}{ }^{+}$SW480 cells decreased from $70.234 \%$ to $22.232 \%$. The reason for the decrease in the survival rate is that resveratrol promotes apoptosis of tumor stem cells and tumor cells. ${ }^{25} \mathrm{~A}$ decrease in the sensitivity of 5-FU to resveratrol indicates that resveratrol confers drug resistance, and it can be seen in Fig. 6 that the effect of drug resistance is positively correlated with the dose of resveratrol. The next step is to explore the mechanism of resveratrol in this process from the aspects of genetic pathway screening and in vivo research.

\section{MTT assay validates the effect of resveratrol on the drug resistance of LoVo stem cells}

Table 3 shows the results of the reaction of different concentrations of 5-FU with the same concentration of resveratrol according to the MTT assays. Table 4 shows the results of the reaction of the same concentration of 5-FU with different concentrations of resveratrol according to the MTT assays.

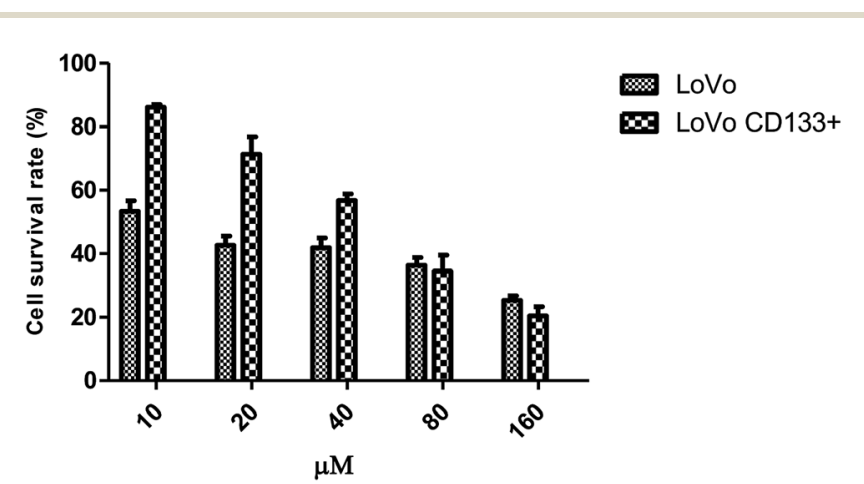

Fig. 7 Effect of FU on the survival rate of LoVo cells and LoVo tumorigenic stem cells.
As shown in Fig. 7, the concentration of 10, 20, 40, 80, and $160 \mu \mathrm{M}$ of 5-FU acts on the LoVo CD133 ${ }^{+}$and LoVo colon cancer cells; the LoVo $\mathrm{CD} 133^{+}$cells have a higher survival rate than the LoVo cells. In a certain range, the same concentration of 5-FU acts on $\mathrm{CD} 133^{+}$LoVo and LoVo colon cancer cells; CD133 ${ }^{+}$LoVo cells have a higher survival rate than the LoVo cells; therefore, CD $133^{+}$LoVo cells are more resistant to drugs than the parental cells. The calculated $\mathrm{IC}_{50}$ of 5-FU for the LoVo cells is $13 \mu \mathrm{M}$ and that for the CD133 ${ }^{+}$LoVo cells is $48 \mu \mathrm{M}$. This indicates that the CD $133^{+}$LoVo cells are more resistant to drugs than the parental cells.

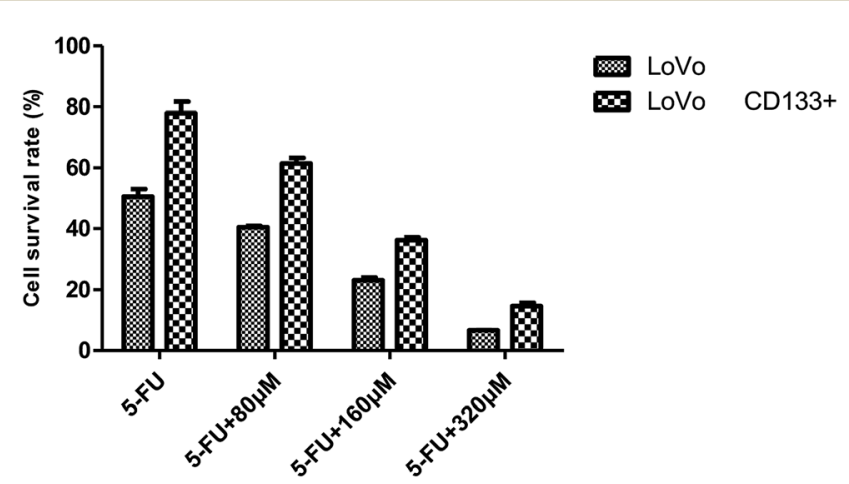

Fig. 8 Bar graph of survival rate of LoVo cells and LoVo CD $133^{+}$cells with $5-\mathrm{Fu}+$ resveratrol.
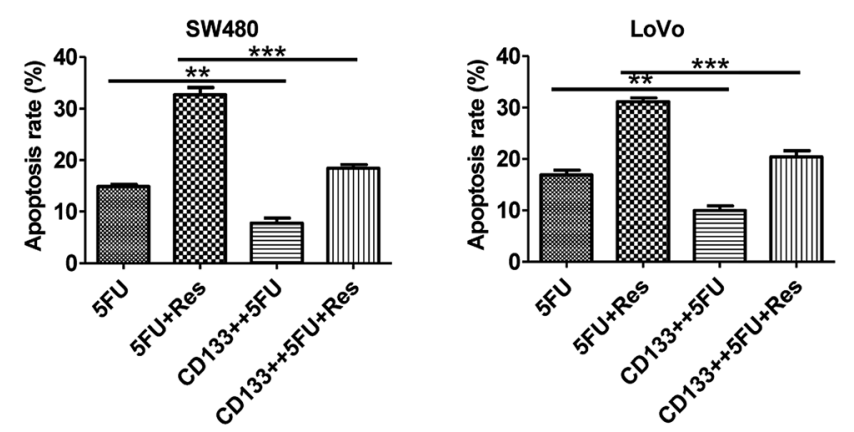

Fig. 9 SW480 cell and LoVo cells' flow apoptotic data histogram (** indicates significant difference; $* * *$ indicates a very significant difference). 


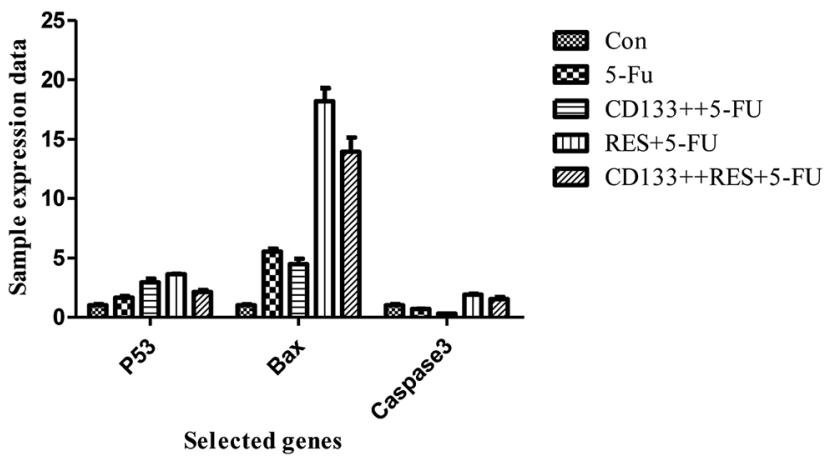

Fig. 10 Expression data of $p 53, B A X$ and other genes in LoVo cell line samples.

As shown in Fig. 8, it was found that 5-FU combined with resveratrol acted on LoVo colon cancer cells and the isolated $\mathrm{CD}_{133^{+}}$LoVo colon cancer stem cells. With an increase in the resveratrol concentration, the LoVo cell survival rate decreased from $50.512 \%$ to $6.622 \%$ and the CD $133^{+}$LoVo cell survival rate decreased to $14.604 \%$ from $77.954 \%$. The reduced sensitivity of 5 -FU to resveratrol indicates that resveratrol confers drug resistance, and it can be seen from Fig. 8 that the effect of drug resistance is positively correlated with the resveratrol dose.

From the data presented in Fig. 9, it can be concluded that 5FU alone acts on CD $133^{+}$SW480 colon cancer stem cells, and the apoptosis rate is reduced from $15 \%$ to $10 \%$. When 5 -FU and resveratrol acted on $\mathrm{SW} 480 \mathrm{CD} 133^{+}$, the apoptosis rate decreased from $30 \%$ to $18 \%$, which was significantly different from that of 5-FU only $(P<0.05)$. The same results can be obtained when 5-FU alone and 5-FU combined with resveratrol act on the $\mathrm{CD}_{133^{+}}$LoVo cells. In addition, both the colon cancer stem cells $\left(\mathrm{CD} 133^{+}\right)$and common colon cancer cells have a large difference in apoptosis rates when 5-FU combined with resveratrol is used and when 5 -FU is used alone.

Many studies have been reported on the inhibitory activity of resveratrol and the mechanism of its effect on tumor cells. ${ }^{26,27}$ We also studied the effect of resveratrol on the survival rate of LoVo cells and LoVo CD $133^{+}$cells in the early stage. The results showed that resveratrol has a certain effect of inhibiting the survival on the above two kinds of cells, and this effect is doserelated; we believe that the effect of resveratrol combined with 5 -FU is better than that of only the latter mainly due to the synergistic inhibition by the former.

\section{Resveratrol inhibits the regulation of cancer stem cell} resistance by gene selection

As shown in Fig. 10, all blank and CD133 ${ }^{+}$cells were treated with 5-FU, and the expression of apoptosis-related genes differed (excluding CASP3) $(P<0.05)$; this indicated that the CD133 ${ }^{+}$ group had lower resistance than the blank cells. Moreover, three
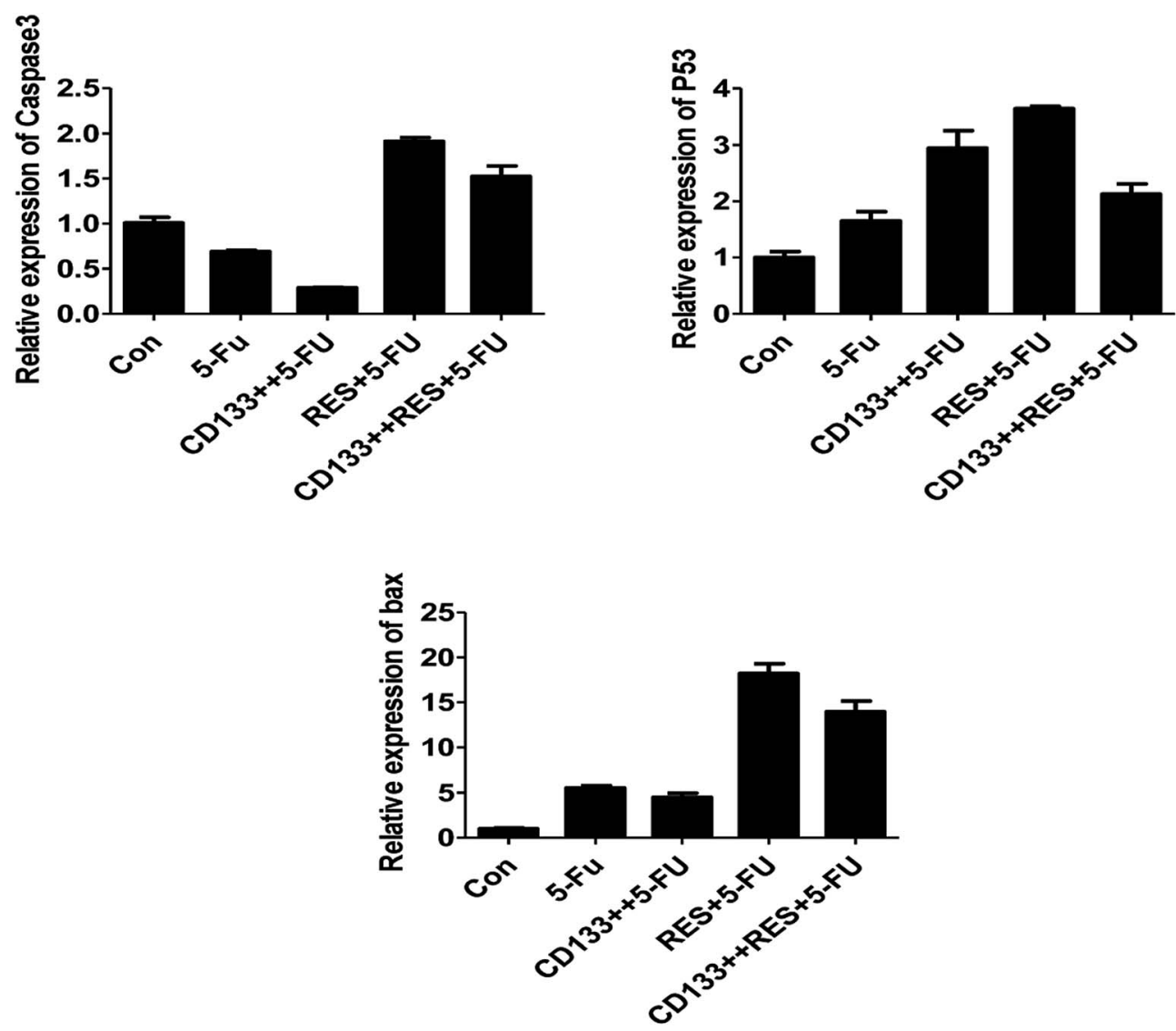

Fig. 11 p53, BAX, CASP3 gene content in LoVo cell line samples. 
selected genes were treated with 5-FU and resveratrol. Only the expression of the $B A X$ gene was significantly increased $(P<0.01)$; this indicated that the gene and resveratrol inhibited the resistance of colon cancer cells to 5-FU. As can be seen from Fig. 11, the normal cells and cancer stem cells in the $B A X$ gene were treated by resveratrol combined with 5-FU and 5-FU alone, and when 5-FU (conventional cell chemotherapy group), $\mathrm{CD}_{133^{+}}+5$-FU (stem cell chemotherapy group), RES + 5-FU (conventional cell chemotherapy + resveratrol group), and $\mathrm{CD} 133^{+}+\mathrm{RES}+5$-FU (stem cell chemotherapy + resveratrol group) were compared, the results showed that resveratrol might regulate stem cell resistance to 5 -FU by regulating apoptosis via the $B A X$ gene.

\section{Conclusion}

The rate of apoptosis is an important indicator of the efficacy of chemotherapeutic drugs. The present study shows that regulation of resveratrol activity can affect the apoptosis induced by chemotherapeutic drugs in tumor cells. Resveratrol has been found to reduce the rate of apoptosis induced by chemotherapeutic agents in breast cancer ${ }^{28}$ although the mechanism of its action is unknown. 5-FU is a basic chemotherapeutic drug used to treat colorectal cancer. Apoptosis is an important indicator of its efficacy. In the present study, resveratrol combined with 5-FU acts on the SW480 and LoVo colon cancer cells, significantly inhibiting the apoptosis induced by 5 -FU.

We found that after sorting, the colon cancer stem cells were more resistant to chemotherapeutic drugs. A possible reason for this is that $\mathrm{CD}_{133^{+}}$cells can escape innate immunity and adaptive immune surveillance, participate in the formation of tumor blood vessels, and activate stem cell-related signaling pathways. The secretion of IL-4 mediates drug resistance and prevents tumor cell apoptosis; this indicates that IL-4 can be used as a marker to identify colorectal cancer stem cells and perform interventional therapy. ${ }^{29,30}$ However, the specific mechanism of its action needs further study.

Resisting or escaping chemotherapy-induced apoptosis is one of the most important mechanisms of chemotherapy resistance in tumors. The results of our experiment show that the inhibition of resveratrol activity reduces the induction of apoptosis in 5-FU cells, and the $B A X$ gene participates in this process. Reports suggest that $B A X$ regulation is involved in the mechanism. $B A X$ is an important suppressor gene in the apoptosis signaling pathway and plays a crucial role in the regulation of apoptosis ${ }^{31}$ via a combination of resveratrol and the $p 53$ and CASP3 genes. 5-FU cell apoptosis experiments show significant differences only regarding the $B A X$ gene, which confirm this theory.

Our experimental results showed that the effects of resveratrol on apoptosis induced by 5-FU in SW480 and LoVo cells were approximately the same. The effect of resveratrol combined with 5-FU on apoptosis in SW480 and LoVo cells and expression of the $B A X$ gene were analyzed. We found that apoptosis in SW480 cells and LoVo cells induced by resveratrol combined with 5-FU was still significant. Resveratrol regulates apoptosis via a combination of 5-FU-regulated $B A X$ genes and is important in the drug tolerance mechanism, but there may also be more complex mechanisms involved.

Based on the abovementioned analysis, we conclude that the apoptosis induced in colon cancer cells by resveratrol is caused by (1) decreased apoptosis resistance; (2) CD133 ${ }^{+}$cells escaping the innate immunity and adaptive immune surveillance and participating in tumor vasculature, and (3) resveratrol and 5-FU combining to regulate the $B A X$ gene to regulate stem cell apoptosis.

\section{Methods}

\section{Materials}

Resveratrol (homemade, 99\%); 5-FU (99\%, HARVEY USA); colon cancer SW480 and LoVo cell line (provided by the Hunan Aijia Biotechnology Company).

\section{Instruments and reagents}

$\mathrm{CO}_{2}$ cell incubator (ThermoFisher Scientific, USA); biosafety cabinet (Heal Force, BIOsafe12); inverted microscope (Motic, AE200); flow cytometer (BD, FACSCanto II); $60 \mathrm{~mm}$ cell culture dish (Corning, 430166); nucleic acid quantifier, mRNA reverse transcription kit, (ThermoFisher Scientific, USA); pancreatic digestion solution (Auragene Corporation), PBS (Auragene Corporation); CD133 MicroBead Kit-Tumor Tissue (MACS Miltenyi Biotec); fetal bovine serum (Gemini).

\section{Selection and isolation of cancer stem cells}

$\mathrm{CD}_{133^{+}}$is a surface-specific marker molecule for stem cells and cancer stem cells. $^{32}$ Therefore, the cancer stem cells used for the study were sorted from normal cells according to the presence of $\mathrm{CD}_{133^{+}}$. Magnetic $\mathrm{CD}_{133^{+}}$stem cells were selected by magnetic sorting.

\section{Flow detection assays}

Each group of cells was digested with an EDTA-free trypsin digestion solution, washed twice with PBS $(2000 \mathrm{rpm}$, centrifuged for $5 \mathrm{~min}$ ), and obtained. Then, $500 \mu \mathrm{L}$ binding buffer suspension cells and $5 \mu \mathrm{L}$ Annexin V-FITC were added, and the solution was mixed. After this, $5 \mu \mathrm{L}$ of propidium iodide was added, and the solution was mixed. The reaction was carried out at room temperature in the dark for 5-15 min. Flow cytometry analysis and detection were performed within $1 \mathrm{~h}$.

\section{Cell balling assays}

The CD133 ${ }^{+}$, LoVo, and SW480 cells were cultured in a cell incubator for $4 \mathrm{~h}$ at $37{ }^{\circ} \mathrm{C}$ and $5 \% \mathrm{CO}_{2}$, then replaced with a spheronization medium and incubated for further $48 \mathrm{~h}$. Individual conglomerate cells were obtained separately and digested with a $0.05 \%$ trypsin digestion solution. A single cell suspension with a percentage of single cells above 95\% was created with the culture medium. Cells were counted, and the cell concentration was diluted to $1 \times 10^{3}$ with a spheronizing medium. Then, $1 \mathrm{~mL}$ of single cell suspension was kept as a spare. $1 \mu \mathrm{L}$ single cell suspension was added to each well of 
a 96-well ultra-low adsorption plate (containing $200 \mu \mathrm{L}$ stem cell medium per well), normal cells and 3 stem cells, each cell total 180 wells ( $200 \mu \mathrm{L}$ PBS in 96-well plate edge wells). The cells were observed using a microscope, and any wells containing no or few cells were removed. The cells were observed daily using the microscope for approximately 6-10 days, and the number and size of the tumors formed was determined.

$$
\begin{aligned}
& \text { Calculation of results : balling rate } \\
& =\frac{\text { number of clones }}{\text { number of inoculated cells }} \times 100 \%
\end{aligned}
$$

\section{SW480 stem cell assays}

Logarithmic phase SW480 and its CD133 ${ }^{+}$stem cells were obtained by trypsinization by adjusting the cell suspension concentration of each group to $5 \times 10^{4}$ cells per $\mathrm{mL}$, then adding $100 \mu \mathrm{L}$ cell suspension to each well of a 96-well plate, and plating the cells for measurement. For $2 \times 10^{4}$ cells per well (peripheral wells were filled with sterile PBS to eliminate edge effects), 5 replicate wells were set in each group. The SW480 parental cell group was first plated and then dosed. The SW480 $\mathrm{CD}_{133^{+}}$cell group was plated the day before and was given the dose the next day. The 5-FU concentrations were 20, 40, 80, 160, and $320 \mu \mathrm{M}$, which were spread the day before and the medicine was added the next day. The concentration of 5-FU was $15 \mu \mathrm{M}$, the concentrations of febutriterol (5-FU) were 80, 160, and 320 $\mu \mathrm{M}$; these were incubated overnight at $37{ }^{\circ} \mathrm{C}$ in a $5 \% \mathrm{CO}_{2}$ incubator. The 96-well plate was removed after every $24 \mathrm{~h}$. The medium was removed, $100 \mu \mathrm{L} 10 \%$ MTT medium was added to each well, and incubated in the cell incubator for $4 \mathrm{~h}$. The medium in the well was carefully aspirated, and $100 \mu \mathrm{L}$ DMSO was added to each well to fully dissolve the crystals. Within 10 min of adding DMSO, the enzyme standard was used. The instrument was tested for absorbance at $570 \mathrm{~nm}$ in each well, and GraphPad data was used. The cell viability and the cell growth inhibition rate were calculated according to the following formulae:

$$
\begin{aligned}
\text { Cell viability }(\mathrm{SR}) \%= & \frac{\text { absorbance of the administration group }}{\text { absorbance of the control group }} \\
& \times 100 \%
\end{aligned}
$$

Cell growth inhibition rate(IR)\%

$$
=\frac{1-\text { absorbance in drug dosage }}{\text { absorbance in control }} \times 100 \%
$$

\section{LoVo stem cell assays}

Log phase LoVo cells and LoVo CD133 ${ }^{+}$stem cells were obtained by trypsin digestion, and the cell suspension concentration was adjusted to $5 \times 10^{4}$ cells per $\mathrm{mL}$ in each group. Then, $100 \mu \mathrm{L}$ of cell suspension was added to each well of a 96-well plate. The cells were measured at $2 \times 10^{4}$ cells per well (peripheral wells were filled with sterile PBS to eliminate the edge effects), and 5 replicates were set in each group. The SW480 parental cell group was first plated and then dosed. The LoVo CD133 ${ }^{+}$cell group was plated the day before and was given the next day. 5-FU concentrations were: $0 \mu \mathrm{M}, 10 \mu \mathrm{M}, 20 \mu \mathrm{M}, 40 \mu \mathrm{M}, 80 \mu \mathrm{M}, 160$ $\mu \mathrm{M}$; 5-FU concentrations were: $15 \mu \mathrm{M}$. These were incubated overnight at $37{ }^{\circ} \mathrm{C}$ in a $5 \% \mathrm{CO}_{2}$ incubator. The 96-well plate was removed after every $24 \mathrm{~h}$. The medium was removed, $100 \mu \mathrm{L}$ of $10 \%$ MTT medium was added to each well, and incubation was carried out in the cell incubator for $4 \mathrm{~h}$. The medium in the well was carefully aspirated, and $100 \mu \mathrm{L}$ DMSO was added to each well to fully dissolve the crystals. Within $10 \mathrm{~min}$ after adding DMSO, the enzyme standard was used. The instrument was tested for absorbance at $570 \mathrm{~nm}$ in each well using GraphPad data. The cell viability and the cell growth inhibition rate were calculated according to the following formulae:

$$
\begin{aligned}
\text { Cell viability }(\mathrm{SR}) \%= & \frac{\text { absorbance of the administration group }}{\text { absorbance of the control group }} \\
& \times 100 \%
\end{aligned}
$$

Cell growth inhibition rate(IR)\%

$$
=\frac{1-\text { absorbance in drug dosage }}{\text { absorbance in control }} \times 100 \%
$$

\section{Flow cytometry assays}

After sorting with $\mathrm{CD} 133^{+}$magnetic beads, the cells were counted and inoculated into 6-well cell culture plates. The next day, flow cytometry was conducted for different concentrations of drugs (5-FU $15 \mu \mathrm{M}$, RES $80 \mu \mathrm{M}$ ). Each group of cells was digested with EDTA-free trypsin digestion solution and washed twice with PBS (2000 rpm, centrifuged for $5 \mathrm{~min}$ ) to obtain the cells. Then, $500 \mu \mathrm{L}$ binding buffer suspension cells and $5 \mu \mathrm{L}$ Annexin V-FITC were added, and the solution was mixed well. After this, $5 \mu \mathrm{L}$ of propidium iodide was added, and mixing was continued. The reaction continued for 5-15 $\mathrm{min}$ at room temperature in the dark. Flow cytometric observation and detection was performed within $1 \mathrm{~h}$.

\section{Real-time PCR analysis}

Real-time PCR was used to detect the expression of $p 53, B A X$, and CASP3 genes in the LoVo cell line samples. The selected genes are all reported to be closely related to colon cancer. ${ }^{33,34}$

Cell lines provided by the cell platform were selected for PCR verification. Herein, $2 \mu \mathrm{g}$ of total RNA from each sample was reverse transcribed to cDNA. The $20 \mu \mathrm{L}$ RT-PCR reaction mixture was as follows: $10 \mu \mathrm{L} 2 \times$ SYBR Green QPCR mix, $1 \mu \mathrm{L}$ each of upstream and downstream primers, $1 \mu \mathrm{L}$ cDNA, and 7 $\mu \mathrm{L}$ water; reaction conditions: pre-denaturation at $95{ }^{\circ} \mathrm{C}$ for 3 min; subsequent denaturation at each step of $95^{\circ} \mathrm{C}, 10 \mathrm{~s}, p 53$, $B A X, C A S P 3$, primer annealing at $60{ }^{\circ} \mathrm{C}$ extended for $30 \mathrm{~s}$ for a total of 40 cycles each time in the extension phase to read the fluorescence value. 


\section{Statistical analysis}

The experimental data were statistically analyzed using the SPSS V17.0 software. The experimental results are expressed as the mean \pm standard deviation. Statistical analysis was performed using the $t$-test to analyze the differences between the groups. The values of $P<0.05$ were considered statistically significant.

\section{Conflicts of interest}

The authors declare no conflict of interest.

\section{Acknowledgements}

This work was supported by National Key R\&D Program of China (2016YFD0600805).

\section{References}

1 A. S. Whittemore, Colorectal cancer incidence among Chinese in North America and the People's Republic of China: variation with sex, age and anatomical site, Health Policy, 1989, 14(2), 563-568.

2 D. M. Parkin, P. Pisani and J. Ferlay, Estimates of the worldwide incidence of eighteen major cancers in 1985, Int. J. Cancer, 1993, 54(4), 594.

3 S. Pathy, R. Lambert, C. Sauvaget, et al., The incidence and survival rates of colorectal cancer in India remain low compared with rising rates in East Asia, Dis. Colon Rectum, 2012, 55(8), 900-906.

4 D. P. Modest, T. Denecke, J. Pratschke, et al., Surgical treatment options following chemotherapy plus cetuximab or bevacizumab in metastatic colorectal cancer-central evaluation of FIRE-3, Eur. J. Cancer, 2018, 88, 77-86.

5 J. S. Huo, S. B. Baylin and E. T. Zambidis, Cancer-like epigenetic derangements of human pluripotent stem cells and their impact on applications in regeneration and repair, Curr. Opin. Genet. Dev., 2014, 28(28), 43-49.

6 B. L. Emmink, A. Verheem, W. J. Van Houdt, et al., The secretome of colon cancer stem cells contains drugmetabolizing enzymes, J. Proteomics, 2013, 91, 84.

7 Y. Yu, G. Ramena and R. C. Elble, The role of cancer stem cells in relapse of solid tumors, Front. Biosci., 2011, 4, 1528-1541.

8 Y. Li, H. A. Rogoff, S. Keates, et al., Suppression of cancer relapse and metastasis by inhibiting cancer stemness, Proc. Natl. Acad. Sci. U. S. A., 2015, $112(6), 1839$.

9 S. T. Fan, Z. F. Yang, D. W. Ho, et al., Prediction of posthepatectomy recurrence of hepatocellular carcinoma by circulating cancer stem cells: a prospective study, Ann. Surg., 2011, 254(4), 569-576.

10 T. Dittmar, C. Nagler, S. Schwitalla, et al., Recurrence cancer stem cells - made by cell fusion?, Med. Hypotheses, 2009, 73(4), 542-547.

11 X. Chen, J. Zhang, Z. Zhang, et al., Cancer stem cells, epithelial-mesenchymal transition, and drug resistance in high-grade ovarian serous carcinoma, Hum. Pathol., 2013, 44(11), 2373-2384.

12 C. Tomasetti and D. Levy, Role of symmetric and asymmetric division of stem cells in developing drug resistance, Proc. Natl. Acad. Sci. U. S. A., 2010, 107(39), 16766-16771.

13 Y. J. Yang, L. Hu, Y. P. Xia, et al., Resveratrol suppresses glial activation and alleviates trigeminal neuralgia via activation of AMPK, J. Neuroinflammation, 2016, 13(1), 84.

14 L. Frémont, Biological effects of resveratrol, Life Sci., 2000, 66(8), 663-673.

15 C. Katona, J. Kralovánszky, A. Rosta, et al., Putative role of dihydropyrimidine dehydrogenase in the toxic side effect of 5-fluorouracil in colorectal cancer patients, Oncology, 1998, 55(5), 468.

16 Y. Z. Chen, Z. D. Li, F. Gao, et al., Effects of combined Chinese drugs and chemotherapy in treating advanced non-small cell lung cancer, Chin. J. Integr. Med., 2009, (6), 415-419.

17 S. Chottanapund, M. B. Van Duursen, P. Navasumrit, et al., Anti-aromatase effect of resveratrol and melatonin on hormonal positive breast cancer cells co-cultured with breast adipose fibroblasts, Toxicol. In Vitro, 2014, 28(7), 1215-1221.

18 J. J. Junco, A. Mancha, G. Malik, et al., Resveratrol and Pglycoprotein inhibitors enhance the anti-skin cancer effects of ursolic acid, Mol. Cancer Res., 2013, 11(12), 1521.

19 F. Amiri, A. H. Zarnani, H. Zand, et al., Synergistic antiproliferative effect of resveratrol and etoposide on human hepatocellular and colon cancer cell lines, Eur. J. Pharmacol., 2013, 718(1-3), 34-40.

20 L. H. Engelke, A. Hamacher, P. Proksch, et al., Ellagic Acid and Resveratrol Prevent the Development of Cisplatin Resistance in the Epithelial Ovarian Cancer Cell Line A2780, J. Cancer, 2016, 7(4), 353.

21 S. H. Kweon, J. H. Song and T. S. Kim, Resveratrol-mediated reversal of doxorubicin resistance in acute myeloid leukemia cells via downregulation of MRP1 expression, Biochem. Biophys. Res. Commun., 2010, 395(1), 104-110.

22 J. Xu, D. Liu, H. Niu, et al., Resveratrol reverses doxorubicin resistance by inhibiting epithelial-mesenchymal transition (EMT) through modulating PTEN/Akt signaling pathway in gastric cancer, J. Exp. Clin. Cancer Res., 2017, 36(1), 19.

23 M. Jie, F. Guo, H. Xu, et al., Combination Therapy using Coencapsulated Resveratrol and Paclitaxel in Liposomes for Drug Resistance Reversal in Breast Cancer Cells In Vivo, Sci. Rep., 2016, 6, 22390.

24 S. Atashpour, S. Fouladdel, T. K. Movahhed, et al., Quercetin induces cell cycle arrest and apoptosis in $\mathrm{CD}_{133^{+}}$cancer stem cells of human colorectal HT29 cancer cell line and enhances anticancer effects of doxorubicin, Iran. J. Basic Med. Sci., 2015, 18(7), 635-643.

25 Y. Li, C. M. BäCkesjö, L.-A. Haldosén, et al., Resveratrol inhibits proliferation and promotes apoptosis of osteosarcoma cells, Eur. J. Pharmacol., 2009, 609(1-3), 13-18.

26 M. Mahyar-Roemer, A. Katsen, P. Mestres, et al., Resveratrol induces colon tumor cell apoptosis independently of p53 and precede by epithelial differentiation, mitochondrial 
proliferation and membrane potential collapse, Int. J. Cancer, 2001, 94(5), 615-622.

27 V. Aires, B. Brassart, A. Carlier, et al., A role for peroxisome proliferator-activated receptor gamma in resveratrolinduced colon cancer cell apoptosis, Mol. Nutr. Food Res., 2014, 58(9), 1785-1794.

28 E. Tili, J. J. Michaille, H. Alder, et al., Resveratrol modulates the levels of microRNAs targeting genes encoding tumorsuppressors and effectors of TGF $\beta$ signaling pathway in SW480 cells, Biochem. Pharmacol., 2010, 80(12), 2057-2065.

29 M. Todaro, M. P. Alea, S. A. Di, et al., Colon cancer stem cells dictate tumor growth and resist cell death by production of interleukin-4, Cell Stem Cell, 2007, 1(4), 389.

30 M. G. Francipane, M. P. Alea, Y. Lombardo, et al., Crucial role of interleukin-4 in the survival of colon cancer stem cells, Cancer Res., 2008, 68(11), 4022.
31 H. Y. Xiong, X. L. Guo, X. X. Bu, et al., Autophagic cell death induced by 5-FU in Bax or PUMA deficient human colon cancer cell, Cancer Lett., 2010, 288(1), 68-74.

32 F. Jing, H. J. Kim, C. H. Kim, et al., Colon cancer stem cell markers CD44 and CD133 in patients with colorectal cancer and synchronous hepatic metastases, Int. J. Oncol., 2015, 46(4), 1582.

33 S. Huerta, X. Gao, S. Dineen, et al., Role of p53, Bax, p21, and DNA-PKcs in radiation sensitivity of HCT-116 cells and xenografts, Surgery, 2013, 154(2), 143-151.

34 S. Chakraborty, M. Mazumdar, S. Mukherjee, et al., Restoration of p53/miR-34a regulatory axis decreases survival advantage and ensures Bax-dependent apoptosis of non-small cell lung carcinoma cells, FEBS Lett., 2014, 588(4), 549-559. 